magnetism, electric potential, and earth temperature. From the Astronomische Nachrichten (No. 48I I) we learn that the 6-in. Repsold heliometer of the Leipsic Observatory was employed by Von Naumann, assisted by Frl. Kuschel, for measures of the position angles of the cusps at chronographically recorded instants through the greatest phase; i 50 measures were obtained in about fifty-two minutes. The following corrections to the ephemerides were obtained :-

$$
d a=+11 \cdot 4^{\prime \prime} \pm 0 \cdot 12^{\prime \prime}, d \delta=-3 \cdot 6^{\prime \prime} \pm 0 \cdot 08^{\prime \prime} .
$$

The solar co-ordinates were taken from the Berliner Jahrbuch; the moon's position was derived from the Nautical Almanac.

Colour Index and Distance of Stars.-Mr. P. J. van Rhijn, who has been working at the Mount Wilson Observatory, has presented an important memoir to the University of Groningen as thesis for doctorate dealing with the change of colour with distance and apparent magnitude, including a new determination of the mean parallaxes of the stars of given magnitude and proper motion. The stellar data employed in the paper are:-(I) Colour or photographic and visual magnitude; (2) spectral type; (3) distance. Colour and spectral type have been taken from the Yerkes actinometry. Distance has been determined according to Kapteyn's method of deriving mean parallaxes from proper motions and magnitudes, and then calculating the mean distances on the hypothesis that the logarithms of the ratio of true parallax to the most probable parallax of stars having the same magnitude and proper motion are distributed according to the law of errors. The data permitted these values to be satisfactorily obtained for the helium and second-type stars, but for the A-type paucity of parallaxes necessitated different treatment. As would be expected, Mr. van Rhijn has obtained results in good accord with those of Kapteyn, whilst the exclusion of stars with large angular motions is shown to be responsible for the opposed conclusions reached by Dr. Campbell.

Having obtained numerical expressions for the mean distances of the stars, Mr. van Rhijn proceeds to deal with the colour index. This has been taken as the summation of the effect of distance and apparent magnitude, the effect of absolute magnitude for various reasons having been given a zero coefficient. Out of the laborious calculations involved in the solution of the colour index equations the following results have emerged. The faint stars, and also the distant stars, are, ceteris paribus, redder than the bright stars and the near stars respectively. The increase of the colour index found being $+0.025 \mathrm{~m} . \pm 0.004$ per cent. per unit of visual magnitude, and $+0.00015 \mathrm{~m} . \pm 0.00003$ per cent. per unit of distance (parsec).

It is possible that the B stars and also the early A stars are immune from the distance effect. If that were so, the coefficient for the remaining spectral types would be increased to a value 6.5 times its probable error. The effect may be due either to an absorption of light in interstellar space or to an influence of absolute magnitude on colour.

\section{RECENT STUDIES OF CERTAIN TROPICAL DISEASES.}

$\mathrm{M}^{\mathrm{ANY}}$

ANY features of much interest are presented in the current number of the Annals of Tropical Medicine and Parasitology (vol. ix., No. 2, June 30). The opening article, by Dr. Breinl, deals with the ulcerative disease known as Gangosa, or Rhinopharyngitis mutilans, as observed by him in New Guinea. The causal agent of the disease is considered to be a new species of Cryptococcus (C. mutilans), of which illustrations are given in a coloured plate. The ravages due to Gangosa are forcibly demonstrated by three plates of photographs of different cases. The second paper, by Dr. H. Priestley, deals with Theileria tachyglossi, a protozoan parasite found in the blood and internal organs of an Echidna, Tachyglossus aculeatus, from the neighbourhood of Townsville, Queensland. This article is of interest as being the first record of the organism from marsupials. The parasite closely resembles Theileria parva of African East Coast fever in cattle. A coloured plate depicts the forms of the parasite observed.

The investigation into the causes of the prevalence of typhoid or enteric fever in Kingston, Jamaica, is ably set forth by Dr. H. H. Scott in the third paper. The mode of infection of food and milk supplies and the means of detection of unrecognised carriers of the typhoid bacillus are described, and should be of service to workers both at home and in the tropics. Water supplies and sewage disposal are also considered. The post-mortem findings and the results of cultivation of the bile from 120 consecutive autopsies are given in tabular form. Eighty more cultivations have since been made. From the total of 200 there have been six cases from which the bacillus has been isolated, apart from those subjects who showed postmortem signs of enteric fever. There are also numerous charts showing the seasonal prevalence of the disease in Kingston.

Another paper by Dr. Breinl deals with the occurrence of various diseases prevalent on the coastal belt of British New Guinea. Eight plates of photographs illustrate the article. Certain diseases, such as malaria, are already known there, but less work has been done on others. Leprosy, filariasis, various curious fevers, juxta-articular nodules, yaws, tropical ulcers, contracting sores, destructive interdigital ulcers, and gangosa have been found among the natives. Only the regional distribution of the maladies has so far been attempted in any detail. New Guinea should provide a rich field for further research in tropical medicine.

The concluding paper is by Dr. Fantham, and deals with insect flagellates and the evolution of disease, with a plea for the recognition of the importance of comparative methods in the study of protozoology. The leishmaniases are used in illustration, and their origin from insect flagellates which are able to adapt themselves to life in vertebrates is discussed. The significance of the herpetomonad flagellate stage of Leishmania, and the existence of such a stage in man, at any rate in $L$. tropica, is indicated. The discovery of natural herpetomonads in mice by Dutton and Todd and by Fantham and Porter is recalled, as well as the occurrence of herpetomonads pathogenic to plants (Euphorbia spp.). The recent striking experiments of Laveran and Franchini on the introduction of herpetomonads into mammals, and of Fantham and Porter on the introduction of these flagellates into mammals, reptiles, amphibia, and fishes are summarised. In these experiments the evolution of the disease, that is, "leishmaniasis in the making," is revealed.

\section{THE TALGAI SKULL.}

PERHAPS the most remarkable incident of the meeting of the British Association in Australia last year was the demonstration given by Profs. Edgeworth David and Wilson to Section $H$ in Sydney of a completely mineralised skull found in the neighbourhood of Talgai in the Darling Downs, Queensland. When war broke out anil Prof. Wilson

NO. 2393, VOL. 96] 
had to devote himself to military duties, Dr. Arthur Smith was appointed acting-professor of anatomy in the University of Sydney, and Colonel Wilson most magnanimously handed over to him this most important human relic for investigation and description. With the valuable assistance of Mr. D. M. S. Watson he has succeeded in removing the matrix and fully exposing the extraordinary features of Australia's earliest known human inhabitant, perhaps a member of the earliest family to ferry across Wallace's line and tramp dogs through Papua to Queensland.

The skull has been purchased by the Hon. Joynton Smith, M.L.C., and presented by him to the University of Sydney. The formal presentation was made the occasion of a public meeting in the University on June I8, presided over by the chancellor, when ActingProf. Arthur Smith and Prof. David delivered addresses on the significance of the skull and its bearing upon the problems of man's antiquity in Australia.

Prof. David explained that the skull (of the Pleistocene period) was found after a flood thirty-one years ago in the bed of a creek near Talgai station, on the Darling Downs, by a stockman. From its highly mineralised state and mode of occurrence in a region where other fossil remains had also been found, the skull was of sufficiently striking geological antiquity to be grouped with the last ice epoch of the northern hemisphere. At the close of the last glacial period, gigantic animals became extinct, and probably the big animals known to have existed in Australia ages ago likewise died at the same time as those of the northern hemisphere. The discovery of the skull might serve to explain how it was that Australia, with its marsupial fauna, had an invader in the form of the dingo, which was a sort of Asiatic jackal, and "had no more right here than the Germans had in Belgium." There was the possibility of its having been brought here by early man. However, the skull was worth its weight in gold. The University of Sydney and men of science throughout the world were under a deep debt of gratitude to Mr. Smith for purchasing the skull, which was undoubtedly a priceless specimen.

Acting-Prof. Smith stated that the condition of the teeth was such as to show that the skull was a youth's, while at the same time it had many of the characteristics of an adult skull. The canine tooth of the Talgai fossil was the largest human tooth so far discovered. The extremely primitive characteristics were such as to warrant one claiming for the skull considerable importance in anthropology, and worthy of being placed with such specimens as the prehistoric Heidelberg jaw and the Piltdown skull. There was, he concluded, certain to be a great controversy concerning the latest discovery when the results of the investigation were made known.

\section{THE RAINFALL OF JAVA.}

I YING as it does midway between India and Lustralia, Java forms a climatological link between the two great British Dominions, and we recognise the appropriateness of the compliment implied in the choice of English as the second language in which this important outcome of Dutch enterprise is published. Tables are given of the mean monthly rainfall, number of rain days, and mean daily maximum rainfall (for each month) at I06I stations in Java from observations taken between

1 "Uitkomsten der Regenwaarnemingen op Java." (Results of Rainfall Observations in Java). By Dr. W. van Bemmelen. Pp. xxiii+r73; Regenatlas (Rainfall-Atlas)
Drukkerij, $\mathrm{x}^{2} \mathrm{x}_{4}$ and 1915. ) No. 2393, VOL. 96]
I879 and I9II. Dr. van Eemmelen discusses the trustworthiness of the data, which are far from uniform. Obviously fallacious records have been eliminated, and there is reason to believe that the data here given compare well with those available for other tropical countries. Observations were made to the nearest millimetre, so that the critical rainfall which determines whether or not a day is to be counted as a rain day is $0.5 \mathrm{~mm}$., or 0.02 in., i.e. four times the amount taken as determining a rain day in this country. As an example of the variability of monthly rainfall in Java, the case is cited of one station where in September, 1902, the rainfall was $12 \mathrm{~mm}$., and in September, r904, $896 \mathrm{~mm}$. The greatest average annual rainfall recorded at any station in Java is $8305 \mathrm{~mm}$., and the least $882 \mathrm{~mm}$., but for both stations quoted the average was only for the short period of seven years and experience shows that runs of seven years may occur with every year above or every year below the long-period average. The wettest year ever recorded at any station was Io, I $2 \mathrm{~mm}$. at Sirah Kentjong, Kediri, in rgog, and the greatest fall in twenty-four hours was $511 \mathrm{~mm}$. at Besolkor, Semarang, on January 3I, IgoI. Perhaps I may be pardoned if I remind those who keep metric and vulgar statistics in separate compartments of their brains that these figures are equivalent to $398 \cdot I$ and $20 \cdot I$ in. respectively.

The most important part of Dr. van Bemmelen's work is his series of maps of average rainfall. That he was fully alive to the difficulties in his way is made plain by his quotation of the reasons which deterred him in 1908 from making the attempt. To our mind the greatest difficulty, and one that has not been overcome, is the use of averages of varying lengths without reduction to a common period. We agree with the author that such reduction was difficult, if not impossible, in the circumstances, and that any sort of isohyetal map is better than none, and for many purposes, both scientific and economic, the maps he has produced will prove most useful. He gives a large-scale ( $1: 1,000,000)$ map showing the position of the stations, and a series of smaller maps (scale $I: I, 500,000)$ for annual rainfall, and the mean monthly rainfall of four selected seasons. These are :-(I) the mean of the three wettest months, December, January, February, when the west monsoon is blowing; (2) the mean for the two months March and April, showing the main transition; and (3) the mean for the two months May and June, when the transition is almost complete, to (4) the period of the east monsoon, represented by the mean of the three months July, August, September-the driest part of the year; finally, (5) the mean of October and November, showing the transition to the wet season again. These maps are admirably executed and most suggestive; but we are of opinion that both the climatic transitions and the geographical distribution would be more clearly suggested by maps based on the homogeneous average of, say, the last ten years, than on the data actually used. We are in hearty agreement with Dr. van Bemmelen's method of drawing isohyetal lines from such data as are available by what he aptly terms " a continual compromise between deduction and induction," the deduction being based on the recognised relationship between configuration, wind-direction, and rainfall, the induction being from the data which have been actually observed. Even where the data are as numerous, long-continued, and reasonably accurate as they are for the British Isles, the most probable distribution of rainfall can only be represented cartographically by such a "continual compromise."

Hugh Robert Mill. 